\title{
GCU
}

Glasgow Caledonian

University

University for the Common Good

\section{Risk of suicidal thinking in caregivers of people with dementia should be assessed and} monitored by health professionals

Parkinson, Ben

Published in:

Evidence Based Nursing

DOI:

10.1136/eb-2018-102930

Publication date:

2018

Document Version

Author accepted manuscript

Link to publication in ResearchOnline

Citation for published version (Harvard):

Parkinson, B 2018, 'Risk of suicidal thinking in caregivers of people with dementia should be assessed and monitored by health professionals', Evidence Based Nursing, vol. 21, no. 3, pp. 73. https://doi.org/10.1136/eb2018-102930

\section{General rights}

Copyright and moral rights for the publications made accessible in the public portal are retained by the authors and/or other copyright owners and it is a condition of accessing publications that users recognise and abide by the legal requirements associated with these rights.

Take down policy

If you believe that this document breaches copyright please view our takedown policy at https://edshare.gcu.ac.uk/id/eprint/5179 for details of how to contact us. 


\section{Category:}

\section{Study type:}

\section{Declarative title:}

Citation: Joling KJ, O'dwyer ST, Hertogh CM, van Hout HP. The occurrence and persistence of thoughts of suicide, self-harm and death in family caregivers of people with dementia: a longitudinal data analysis over 2 years. International journal of geriatric psychiatry. 2018 Feb;33(2):263-70.

\section{Commentary}

\section{Implications for practice and research}

- This research provides further evidence of the importance of asking carers about their mental health and whether they experience suicidal thoughts.

- Researchers should add to this work by exploring the relationship between suicidal thinking, planning, intent, and attempts at suicide for caregivers for people living with dementia.

\section{Context}

The number of people with dementia and being cared for by family caregivers in the community is growing ${ }^{1}$. Behavioural and psychological issues associated with dementia make the caregiver role potentially burdensome and mean some caregivers experience mental health difficulties and/or suicidal ideation $^{2}$. Previous research suggests $16 \%$ of caregivers supporting someone living with dementia might experience suicidal ideation, which highlights the scale of the problem and importance of this research topic ${ }^{3}$. Joling and colleagues ${ }^{4}$ research takes a longitudinal perspective on the subject and examines the occurrence and persistence of suicidal thoughts among caregivers for people living with dementia.

\section{Methods}

This longitudinal analysis used data from a study completed in the Netherlands during 2007-20095. The original study recruited participants who provided care for someone living with dementia, but excluded any carers with anxiety and depression. The study collected baseline data and completed the Mini International Neuropsychiatric Interview (MINI) ${ }^{6}$ every three months for two years. Suicidal thinking was measured using the $\mathrm{MINI}^{6}$, but this only occurred if someone indicated possible depression and involved asking a single question about suicide.

The analysis divided the sample into three groups: those with depressive symptoms and suicidal thoughts; those with depressive symptoms, but no suicidal thought, and those without depressive symptoms and were not assessed for suicidal thoughts. Statistical analysis was undertaken to determine the baseline characteristic of the caregivers within each of these groups.

\section{Findings}


The sample of 192 participants consisted of mostly older (mean 69.5 years) female caregivers ( $70.3 \%$ female), who were caring for a spouse with a recent diagnosis of dementia (mean 1.1 years), and milder cognitive impairment

During the study 76(39.6\%) caregivers reported depressive symptoms and were assessed for suicidal thoughts. 9(4.7\%) caregivers reported suicidal thinking and 3(1.6\%) experienced suicidal thinking on more than one occasion. In $7(3.6 \%)$ cases the suicidal thoughts occurred in the second year of the study. Suicidal thinking appeared related to severity of anxiety/depression symptoms, perceived levels of competence, health difficulties, less family support, and loneliness.

\section{Commentary}

This study illuminates the issue of suicidal thinking amongst caregivers for people with dementia by providing a useful longitudinal perspective of the subject. The most important findings relate to the occurrence and persistence of suicidal thinking and the rate of occurrence/recurrence for some people. The study indicates $4.7 \%$ of the total sample experienced suicidal thoughts, which is slightly lower than the $16 \%$ reported in a similar cross-sectional survey $^{3}$. However, this study did not include people with pre-existing anxiety or depression and the assessment of suicidal thinking relied on one question, which was only asked of $39.6 \%$ of participants. These factors mean the current study might have underestimated the true extent of suicidal thinking within this population ${ }^{4}$. It is also worth remembering not everyone who experiences suicidal thinking will plan or intend to harm themself, which means it is necessary to explore the issue more thoroughly before making firms assertions about the nature and extent of suicidality within this population $^{2 \& 4}$.

Health professionals should take cognisance of the fact caregivers can experience depressive symptoms and/or suicidal thoughts when caring for someone with dementia and ensure they regularly ask about depressive symptoms and suicidal thinking as part of the routine assessment and monitoring. Further research should thoroughly explore the relationship between suicidal thinking, planning, intent, and attempts at suicide.

\section{References}

1. McCabe M, You E, Tatangelo G. Hearing their voice: A systematic review of dementia family caregivers' needs. The Gerontologist. 2016 Apr 21;56(5):e70-88.

2. O'Dwyer S, Moyle W, Van Wyk S. Suicidal ideation and resilience in family carers of people with dementia: A pilot qualitative study. Aging \& Mental Health. 2013 Aug 1;17(6):753-60.

3. O'Dwyer, S.T., Moyle, W., Zimmer-Gembeck, M. and De Leo, D., 2016. Suicidal ideation in family carers of people with dementia. Aging \& mental health, 20(2), pp.222-230.

4. Joling KJ, O'dwyer ST, Hertogh CM, van Hout HP. The occurrence and persistence of thoughts of suicide, self-harm and death in family caregivers of people with dementia: a longitudinal data analysis over 2 years. International journal of geriatric psychiatry. 2018 Feb;33(2):263-70.

5. Joling KJ, van Marwijk HW, Smit F, van der Horst HE, Scheltens P, van de Ven PM, Mittelman MS, van Hout HP. Does a family meetings intervention prevent depression and 
anxiety in family caregivers of dementia patients? A randomized trial. PloS one. 2012 Jan 27;7(1):e30936.

6. Sheehan DV, Lecrubier $\mathrm{Y}$, Sheehan $\mathrm{KH}$, et al. The Mini-International Neuropsychiatric Interview (MINI): the development and validation of a structured diagnostic psychiatric interview for DSM-IV and ICD-10. J clin psychiatry. 1998;59(Suppl 20):22-33.

\section{Commentator details}

Name: Ben Parkinson

Affiliation: Glasgow Caledonian University

Correspondence address: Glasgow Caledonian University, Cowcaddens

Road, Glasgow, G4 OBA, United Kingdom.

Email: ben.parkinson@gcu.ac.uk

\section{Competing interests}

None 